\title{
NWS FROST DEPTH OBSERVATION WITH LIQUID-IN PROBES PERFORMANCE: TWO-YEAR REVIEW
}

\author{
F. Adnan Akyüz \\ North Dakota State University \\ Mark Ewens \\ National Weather Service \\ Grand Forks Weather Forecast Office
}

Radu Carcoana and Barbara Mullins

North Dakota State University

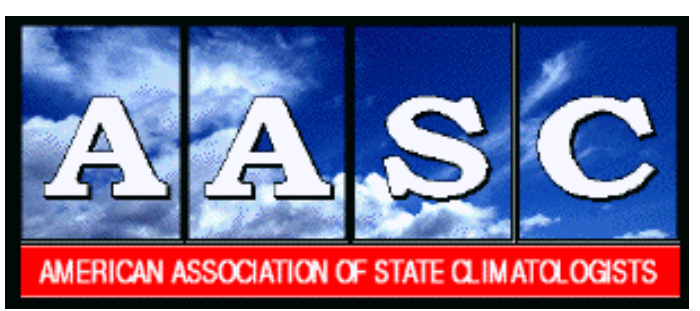

2008

Journal of Service Climatology

Volume 2, Number 2, Pages 1-10

A Refereed Journal of the American Association of State Climatologists 


\title{
NWS Frost Depth Observation with Liquid-In Probes Performance: Two-Year Review
}

\author{
F. Adnan Akyüz \\ North Dakota State University \\ Mark Ewens \\ National Weather Service \\ Grand Forks Weather Forecast Office \\ Radu Carcoana and Barbara Mullins \\ North Dakota State University
High Plains Regional Climate Center
School of Natural Resources
University of Nebraska

Corresponding Author: Adnan Akyüz . School of Natural Resource Sciences, 106 Walster Hall, North Dakota State University, Fargo, ND 58107, USA. Tel. 1-701-231-6577, Adnan.Akyuz@ndsu.edu.

(Non-technical summary is at the end of this paper)

\begin{abstract}
Performance of the liquid-in frost depth probe made in-house by the Grand Forks National Weather Service (NWS) Weather Forecast Office (WFO) is compared against soil temperature observations made by North Dakota Agricultural Weather Network (NDAWN) at the Fargo location for a two-year period from 2006-2007 to 2007-2008 winter seasons. While the liquid-in frost depth probe provided continuous frost depth observations, NDAWN soil temperature observations had to be interpolated between measurement points to determine the depth where the soil temperature was $0{ }^{\circ} \mathrm{C}\left(32^{\circ} \mathrm{F}\right)$. In general, the trends of both observations matched almost identically; however, the magnitude of the depths varied with liquid-in frost depth probe consistently showing deeper frost depths than the NDAWN soil temperature observations. Differences are discussed further in the following sections.
\end{abstract}




\section{The Observation Site}

The North Dakota Agricultural Weather Network (NDAWN) station number one (1) in Fargo is located on 0.6 hec (1.5 acres) of flat, grassy terrain just to the west of the North Dakota State University (NDSU) campus and less than $1.6 \mathrm{~km}$ (one mile) south of Fargo Hector International Airport (4653'50.44"N, 96² 48' 43.65"W), NDSU Microclimate Research Station (MRS). The observation area in NDSUMRS is $67 \mathrm{~m}$ (220 feet) by $98 \mathrm{~m}$ (320 feet). It is protected with wire-fence to stop curious passers-by tampering with the sensors. The observation site is a host site to other research instruments such as UV-B station number 27 (USDA, 2008), lysimeter (Casey et al., 2008), and others (Smerdon et al., 2006; Smerdon et al., 2004; Smerdon et al., 2003; Smerdon et al., 2002; and Schmidt et al., 2001). In addition, the NDAWN station at this site interfaces with a deep soil moisture profile that samples soil temperature data at multiple depths from $1 \mathrm{~cm}$ to $11.7 \mathrm{~m}$. Therefore, it was a natural choice for the National Weather Service (NWS) frost depth probe to be placed next to the NDAWN weather station.

\section{North Dakota Agricultural Weather Network (NDAWN) Deep Soil Temperature Profile}

The NDAWN network is comprised of 70 automated weather stations across North Dakota, western Minnesota, eastern Montana and northern South Dakota. All weather stations in the network records hourly basic weather elements: air temperature, rainfall, wind speed and direction, solar radiation, soil temperature at $10 \mathrm{~cm}$ (4 inches) under bare and turf conditions, and atmospheric pressure (in most stations). In addition, the NDAWN station in Fargo collects hourly deep soil temperatures at multiple depths. The data have been collected daily since 1992. Type T-thermocouples (Extension grade, copper/constantan, duplex, ANSI type TX) are deployed at 23 different depths: 1, $5,10,20,30,40,50,60,80,100,125,150,175$, 200, 250, 270, 300, 370, 470, 570, 770, 970, $1170 \mathrm{~cm}$ below the ground level.

Figure 1 depicts the measurement points in the profile. These thermocouples can easily be purchased as spools and can be cut to any desired length. Each thermocouple has two leads

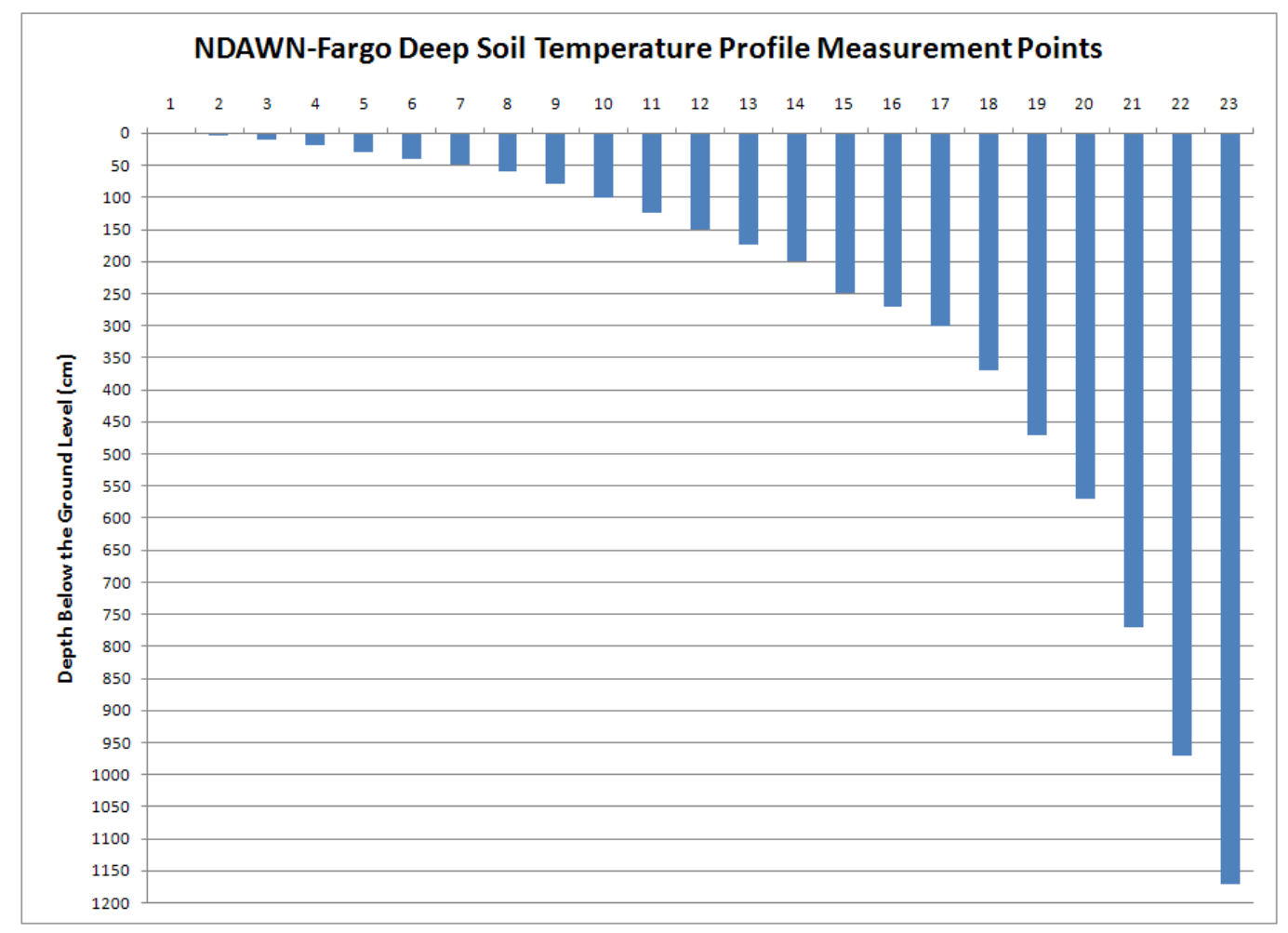

Figure 1. NDAWN-Fargo Station Deep Soil Temperature Profile Measurement Points. 
with dissimilar metals (copper and constantan) that respond to temperature changes as voltage gradient. We then translated those voltage gradients into temperature values using a CR10X datalogger (Campbell Scientific Inc.). Since there were 23 sensors with 46 leads (two leads for each sensor) would require more channels than the datalogger could provide, we added more channels using a 32-channel relay multiplexer that allowed 32 additional differential two-wire sensors at a time.

\section{NWS Frost Depth Observations}

The North Central River Forecast Center (NCRFC) currently uses the Sacramento Soil Moisture Accounting (SAC-SMA) model as part of the Advanced Hydrologic Prediction System (AHPS) suite. The SAC-SMA parameterizes the depth of frozen ground in order to calculate the runoff/absorption ratio during spring snow-melt flood scenarios. In order to gain a better understanding of how the frost within the Red River Valley of the North (RRVoN) actually behaves during the spring snow-melt period, the Weather Service (NWS) in Grand Forks was tasked with the development and deployment of a frost probe network.

The NWS Grand Forks frost probes were developed based on the Brian Hahn (Service Hydrologist, Milwaukee WI) model employed in Wisconsin in 2004-2005. The Hahn model employed a Tygon ${ }^{\mathrm{TM}}$ plastic tube $2.54 \mathrm{~cm}$ by $1.83 \mathrm{~m}$ (1 inch $\mathrm{x} 6$ foot) in size filled with water colored with Orcoacid ${ }^{\mathrm{TM}}$ fluoresciene dye, placed in a $5.1 \mathrm{~cm}$ (2 inch) diameter PVC sleeve, then buried. Orcoacid ${ }^{\mathrm{TM}}$ fluoresciene dye is an orange-colored compound that turns green when mixed with tap water. During the freezing process, the frozen layer becomes clear, making the determination of the frost depth easy.

The NCRFC and NWS Grand Forks selected 16 locations within the RRVoN that would suitably represent the distribution of frost as described by the SAC-SMA. Table 1 provides a list of these locations. The Grand Forks variant differs slightly from the Hahn version, in that we used $1.00 \mathrm{~cm}$ by $1.52 \mathrm{~m}$ (3/8 inch x 5 foot) lengths of Tygon ${ }^{\mathrm{TM}}$ tubing placed in a $1.6 \mathrm{~cm}$ (5/8 inch) PVC housing. Increments of $2.54 \mathrm{~cm}$ ( 1 inch) were drawn on the exterior of the Tygon $^{\mathrm{TM}}$ plastic tubing, and the tube filled to the zero level with the water/Orcoacid ${ }^{\mathrm{TM}}$ fluoresciene dye mixture (Figure 2).

Operational deployment was performed during September and October 2006. Of the 16 total, the original probe was installed at NWS Grand Forks in October 2005 as an Operational Test \& Evaluation. Twelve probes were installed during the fall of 2006, with two additional probes
Table 1. NWS Frost Depth Probe Locations in the Red River Valley of the North.

\section{City/State}

1. Grand Forks, ND NWS

2. Langdon, ND

3. Camp Norris, $\mathrm{MN}$

4. Endmore 1NW, ND

5. Baldhill Dam, ND

6. Thief River Falls, MN

7. North Dakota State University/Fargo ND

8. Casselton Ag. Farm, ND

9. Lisbon, ND

10. Forman, ND

11. Halstad, MN

12. Orwell Dam, MN

13. Campbell, $\mathrm{MN}$

14. Pembina, ND

15. Dalton 3S, MN

16. Devils Lake, ND

installed during the summer of 2007. All probes were co-located with official NWS Cooperative Weather Observation sites. The Fargo probe was installed in July 2006 and the first data were recorded on December 1, 2006.

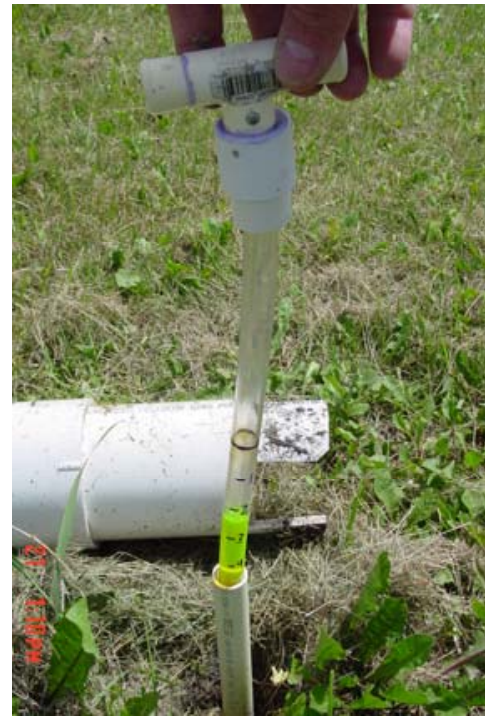

Figure 2. Tygon ${ }^{\mathrm{TM}}$ plastic tube filled with water/ Orcoacid $^{\mathrm{TM}}$ fluoresciene dye mixture

Installation was performed by drilling a 5.1 $\mathrm{cm}$ (2 inch) diameter hole to a depth of $1.82 \mathrm{~m}$ (6 feet). The PVC housing was lowered to a depth of $1.52 \mathrm{~m}$ (5 feet; predetermined by external reference marking), then the hole was backfilled with crystalline silica, commonly called "sandblasting sand". The intent of the 


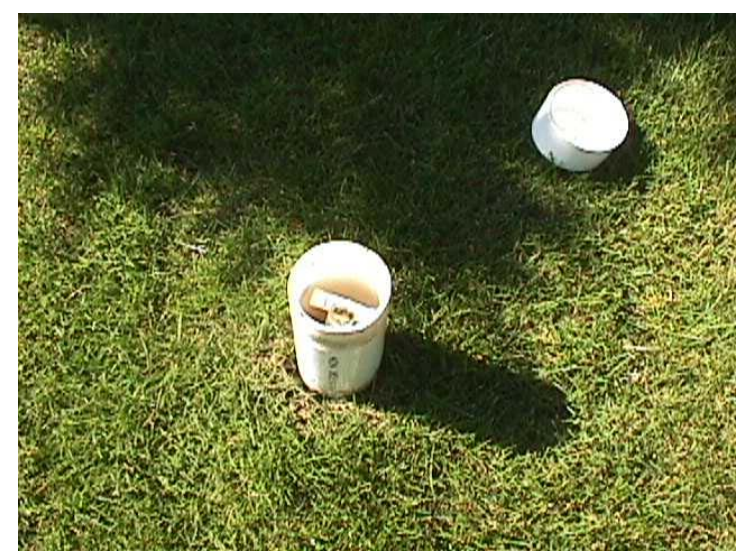

Figure $3.10 \mathrm{~cm}$ (4 inch) protective PVC cover and its lid.

crystalline silica was to offer stability in the core and maintain proper conduction in the soil. The probe was protected by covering the access with a $10 \mathrm{~cm}$ (4 inch) PVC cover and lid (Figure 3).

There are several key assumptions that need be stated as a point of clarification. First is that the Orcoacid $^{\mathrm{TM}}$ fluoresciene dye did not sufficiently modify the specific or thermal density of the water in the probe to affect the freeze rate or natural conductive properties. In this way, the depth measured was accurate. The second critical assumption is that the water/Orcoacid $^{\mathrm{TM}}$ fluoresciene dye mix actually froze at $0{ }^{\circ} \mathrm{C}$. Although most frost data were collected weekly on Monday mornings at the same time as the normal cooperative observation time, the Fargo location collected frost depth measurements at noon. Then the data were transmitted to the Grand Forks NWS office via telephone. Most other observers typically used the WxCoder II web based program (now WxCoder III), or called NWS Grand Forks for encoding and transmission. When requested by the NCRFC, additional data could be collected and transmitted.

\section{Analysis}

As seen in Figure 1, more soil temperature measurement points were selected at depths closer to the surface than deeper into the soil so that the frost depth is captured in the closest proximity to the surface. However, the measurement depths were discrete variables, so exact frost depth had to be interpolated between the measurement points. For example, if the frost depth was between the 10 and $20 \mathrm{~cm}$ levels we used linear, polynomial and logarithmic interpolation to estimate the actual frost depth. All three methods came within 1\% from each other (i.e. $1 \mathrm{~mm}$ difference at $10 \mathrm{~cm}$ depth). Therefore, we used linear interpolation for simplicity if $0{ }^{\circ} \mathrm{C}$ occurred between two measurement points to estimate the frost depth.
We also assumed that the ground would freeze at $0{ }^{\circ} \mathrm{C}$. The authors realized that the assumption might not be applicable when comparing the frost depths among different soils with different water content. We also assumed that when we measured $0{ }^{\circ} \mathrm{C}$ at a depth, the soil would freeze the liquid in the NWS liquid-in frost depth probe.

The ground normally freezes after air temperatures fall below $0{ }^{\circ} \mathrm{C}$ continuously in fall. Radiant and conductive heat exchange occurs at the surface; therefore, there may be some diurnal fluctuation near the surface. However, these diurnal fluctuations decrease rapidly with depth. Heat exchange within soil is through conduction, which occurs very slowly. Frost depth increases with time well into spring in Fargo. When the air temperature reaches above freezing in spring, heat exchange allows ground to thaw at the surface first. At this time, frost depth at the bottom of the frozen layer of soil remains relatively unchanged. As the surface layer of thawed soil deepens in spring, a layer of frozen soil is trapped underneath. Eventually this layer thaws in late spring. Hence, there are two frost depths in the soil at any given time: at the top and the bottom. In fall and winter, the ground is frozen from surface to bottom. Therefore the top depth is zero.

Both the top and the bottom frost depth measurements have different applications. When planting crops, for example, farmers may be interested in top frost depths while the construction industry may be more interested in the bottom frost depths.

We analyzed both the top and the bottom frost depths for a two-year period from fall 2006 to spring 2008. Since the top frost depth is zero in fall, we only analyzed the top during spring seasons. Our analysis was comprised of comparing frost depths measured by the NWS liquid-in frost depth probe with the frost depths estimated by the NDAWN deep soil temperature profile in Fargo, ND. In this study, estimation is attributed to the NDAWN deep-soil temperature profile because the data were not observed in a spatially continuous setting. Actual frost depths were interpolated linearly within the profile using two measurement points on each side of the estimated frost depth.

Table 2 is the dataset of two-year side-byside observations of frost depth made in NDSU Microclimate Research Station, Fargo. In the spring of 2008, the NWS frost depth probe showed $5 \mathrm{~cm}$ of missing liquid. Therefore, a missing value was entered if the actual top frost depth was less than $5 \mathrm{~cm}$.

Figures 4 and 5 are the comparison graphs between the NWS frost depth probe and the NDAWN soil temperature profile in the 2006-07 and 2007-08 winter seasons respectively. They both show the bottom frost depths.

Figures 6 and 7 are the comparison graphs between the NWS frost depth probe and the 
Table 2. A Two-year data of the NWS Frost Depth measurement and the NDAWN estimation of frost depth in Fargo, North Dakota (Top and Bottom represent the top and the bottom of the frost layer respectively)

\begin{tabular}{|c|c|c|c|c|}
\hline Date & $\begin{array}{l}\text { Top } \\
(\mathrm{cm})\end{array}$ & $\begin{array}{r}\text { NWS } \\
\text { Bottom } \\
(\mathrm{cm})\end{array}$ & $\begin{array}{c}\text { Top } \\
\text { (cm) }\end{array}$ & $\begin{array}{r}\text { NDAWN } \\
\text { Bottom } \\
\text { (cm) }\end{array}$ \\
\hline $12 / 1 / 2006$ & 0.0 & -12.7 & 0 & -14.5 \\
\hline $2 / 1 / 2007$ & 0.0 & -76.2 & 0 & -53.7 \\
\hline $3 / 5 / 2007$ & 0.0 & -76.2 & 0 & -61.7 \\
\hline 3/12/2007 & -5.1 & -76.2 & 0 & -59.1 \\
\hline 3/19/2007 & -12.7 & -76.2 & 0 & -60 \\
\hline 3/26/2007 & -22.9 & -73.7 & -17.9 & -52.7 \\
\hline 3/28/2007 & -38.1 & -71.1 & -26.3 & -49.9 \\
\hline 3/30/2007 & -30.5 & -71.1 & -28.7 & -50.7 \\
\hline $4 / 2 / 2007$ & -22.9 & -71.1 & -29.4 & -52.5 \\
\hline 4/9/2007 & 0.0 & -71.1 & 0 & -55.8 \\
\hline $4 / 16 / 2007$ & -12.7 & -68.6 & -28.1 & -49.1 \\
\hline $4 / 20 / 2007$ & -40.6 & -66.0 & 0 & 0 \\
\hline $4 / 23 / 2007$ & 0.0 & 0.0 & 0 & 0 \\
\hline 11/26/2007 & 0.0 & 0.0 & 0 & 0 \\
\hline $12 / 6 / 2007$ & 0.0 & -12.7 & 0 & -4.5 \\
\hline $12 / 18 / 2007$ & 0.0 & -20.3 & 0 & -6.6 \\
\hline $12 / 27 / 2007$ & 0.0 & -20.3 & 0 & -8 \\
\hline $1 / 2 / 2008$ & 0.0 & -20.3 & 0 & -14.2 \\
\hline $1 / 8 / 2008$ & 0.0 & -20.3 & 0 & -14 \\
\hline $1 / 14 / 2008$ & 0.0 & -22.9 & 0 & -24.1 \\
\hline $1 / 22 / 2008$ & 0.0 & -38.1 & 0 & -36.3 \\
\hline $1 / 28 / 2008$ & 0.0 & -47.0 & 0 & -43 \\
\hline $2 / 4 / 2008$ & 0.0 & -49.5 & 0 & -51.6 \\
\hline 2/12/2008 & 0.0 & -61.0 & 0 & -55.8 \\
\hline 2/18/2008 & 0.0 & -66.0 & 0 & -63.3 \\
\hline $2 / 25 / 2008$ & 0.0 & -71.1 & 0 & -65.4 \\
\hline $3 / 7 / 2008$ & 0.0 & -76.2 & 0 & -69.7 \\
\hline 3/17/2008 & missing & -81.3 & -9 & -64.4 \\
\hline $3 / 24 / 2008$ & missing & -81.3 & -4 & -63.6 \\
\hline 3/31/2008 & missing & -81.3 & -8 & -62.2 \\
\hline 4/7/2008 & missing & -81.3 & -9 & -60.2 \\
\hline 4/9/2008 & -7.6 & -76.2 & -29 & -63.2 \\
\hline 4/13/2008 & -15.2 & -73.7 & -28 & -57.8 \\
\hline 4/18/2008 & -35.6 & -71.1 & -61.5 & -61.5 \\
\hline $4 / 21 / 2008$ & -48.3 & -71.1 & -60 & -60 \\
\hline 4/23/2008 & 0.0 & 0.0 & 0 & \\
\hline
\end{tabular}

NDAWN soil temperature profile in 2007 and 2008 spring seasons respectively. They both show the top frost depths. In 2008, the NWS frost depth tube had $5 \mathrm{~cm}$ (2 inches) of loss in liquid level. If the frost occurred between the surface and $5 \mathrm{~cm}$ layer, there was no way of knowing where the frost depth was based on NWS frost depth probe, therefore, it was not plotted.

\section{Conclusions}

\section{a. Bottom frost depths}

- Both 2006-07 and 2007-08 winter season experiments indicated that the frost depths measured with the NWS liquid-in frost depth probes were deeper.

- NWS frost depth probe showed less variation with time suggesting time delay in liquid responding the temperature change in the soil.

- Differences between the NDAWN soil temperature profile estimation and the NWS frost depth probe were greater with depth.

- Maximum difference was $66 \mathrm{~cm}$ when the NWS probe measured the bottom of the frost as $66 \mathrm{~cm}$ below surface and the NDAWN soil temperature profile measured no temperatures at or below 0 ${ }^{\circ} \mathrm{C}$ on April 20, 2007. This should not be misinterpreted. It is possible that a thin layer of frozen soil was trapped between the top and the bottom frost depths. When the temperature is at or around 0 ${ }^{\circ} \mathrm{C}$, small differences in temperature measurements with different methods can misleadly appear as big differences in frost depth observations.

- In 2006, the NWS observation was started too late. When the first observation was recorded on December 1 , 2006, the bottom of the frost depth was already $13 \mathrm{~cm}$. In 2007, the first day of the frost was successfully captured.

\section{b. Top Frost Depths:}

- Both measurement methods were highly depended on air temperature since radiant heat exchange between the air and the soil takes place at the surface.

- Seasonal variations of the top frost depths were greater than those of the bottom frost depths.

- In 2008, the NDAWN estimation showed deeper top frost depths than the NWS measurements while in 2007 there was no distinct pattern. 


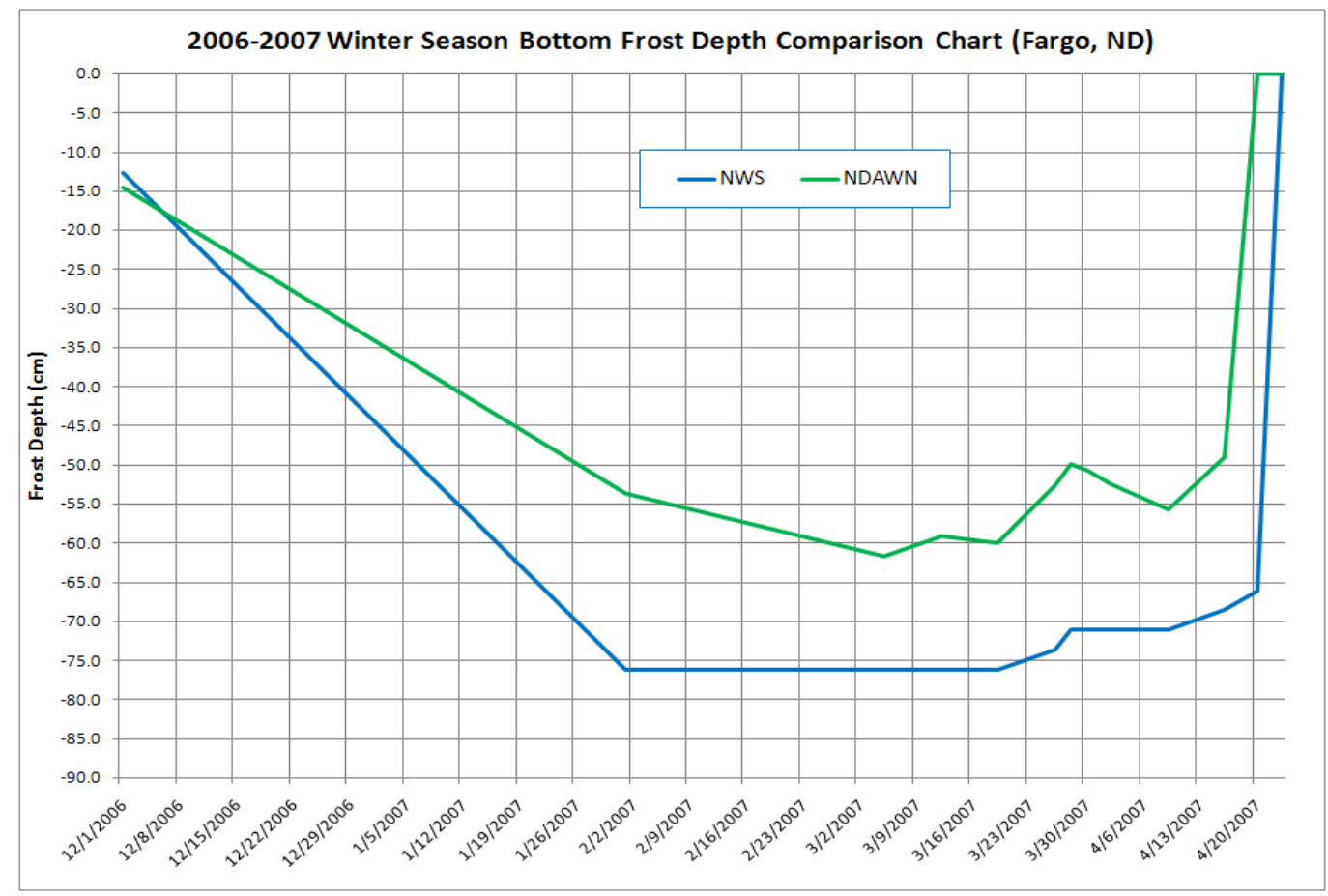

Figure 4. 2006-2007 Winter Season Bottom Frost Depth Comparison between the NWS Frost Probe (blue line) and the NDAWN Deep Soil Temperature Profile (green line).

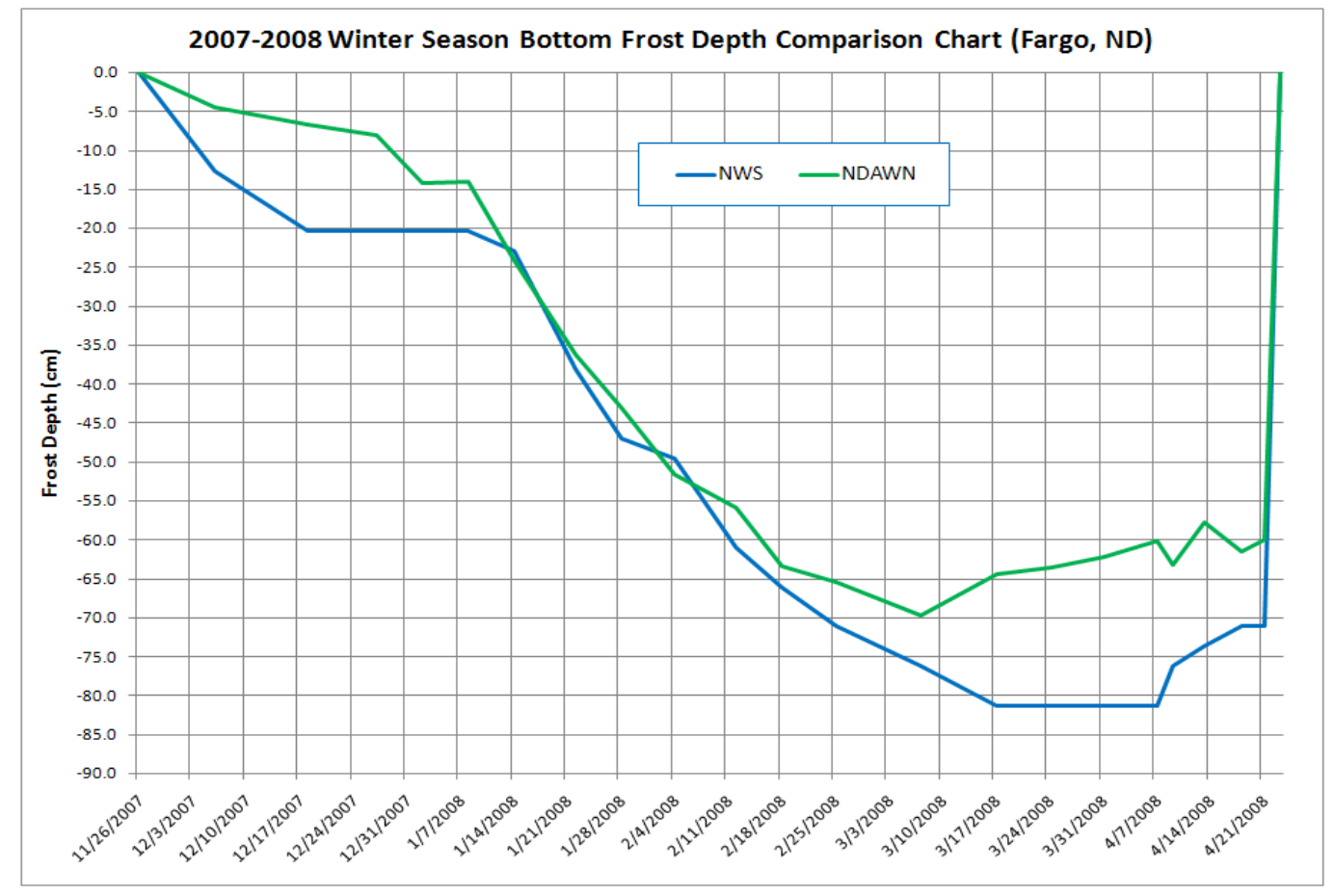

Figure 5. 2007-2008 Winter Season Bottom Frost Depth Comparison between the NWS Frost Probe (blue line) and the NDAWN Deep Soil Temperature Profile (green line). 


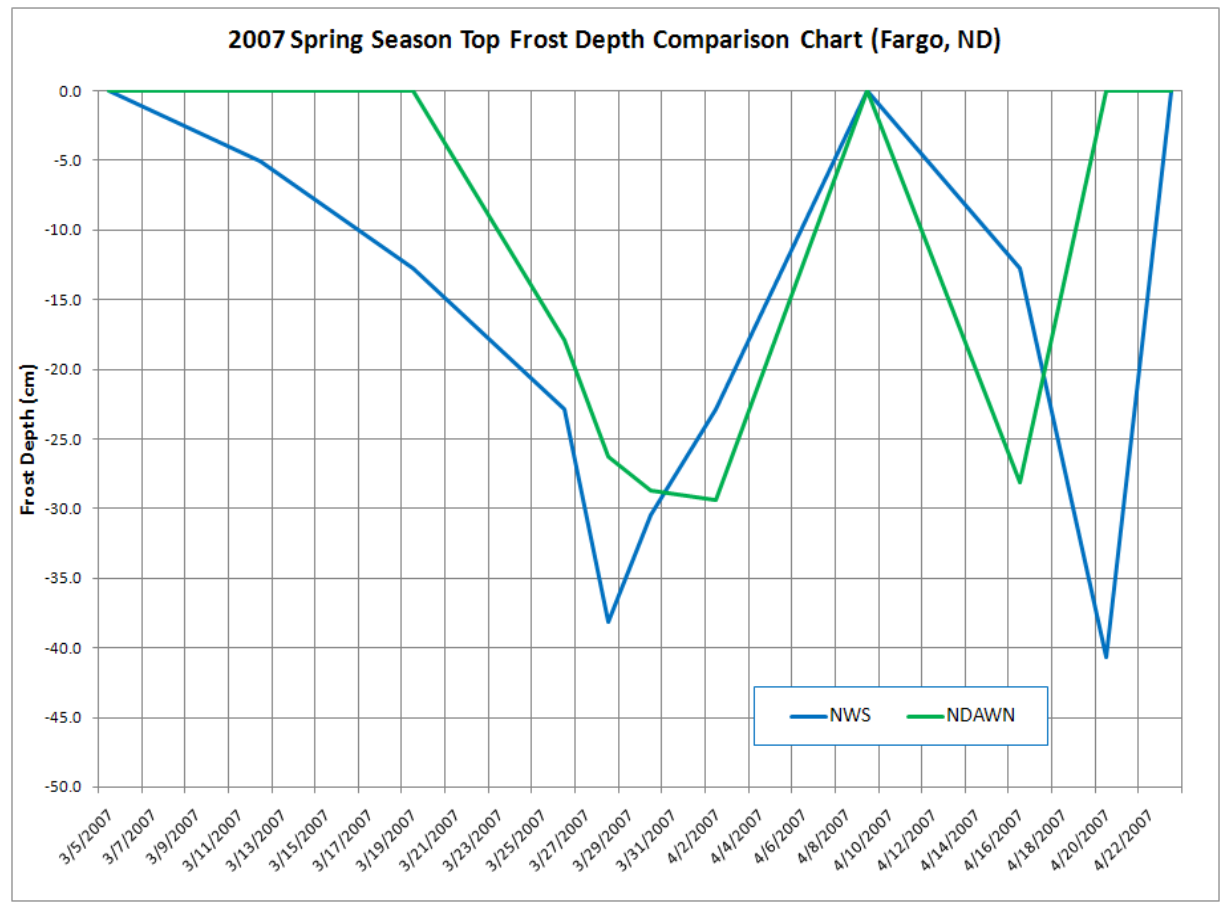

Figure 6. 2007 Spring Season Top Frost Depth Comparison between the NWS Frost Probe (blue line) and the NDAWN Deep Soil Temperature Profile (green line).

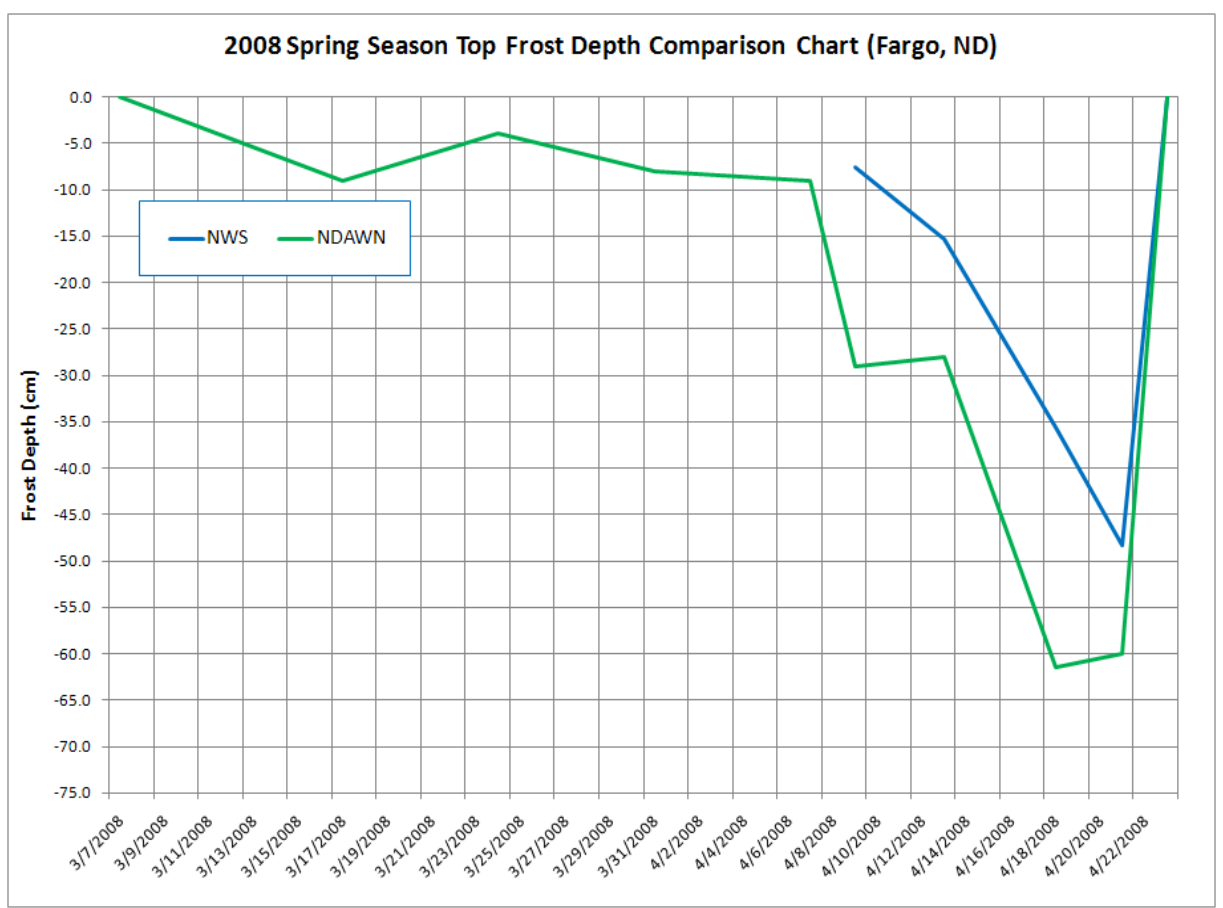

Figure 7. 2008 Spring Season Top Frost Depth Comparison between the NWS Frost Probe (blue line) and the NDAWN Deep Soil Temperature Profile (green line). NWS frost depth tube had 2.5” (5 cm) of loss in liquid level in 2008. Therefore the frost depths above $5 \mathrm{~cm}$ (2 inches) were not plotted. 
- While the NDAWN estimation reached above freezing conditions later than the NWS measurements showed in 2007, it was the opposite in 2008. In fact, when the NDAWN estimation showed that the top frost depth was $9 \mathrm{~cm}$ on April 7, NWS frost depth probe was frozen from 0 to $81 \mathrm{~cm}$ on the same day. The observer noticed that the probe lost 5 $\mathrm{cm}$ of liquid. We believe that if the difference would have been less if the liquid level was sufficient.

\section{c. Recommendation to NWS:}

- When the liquid in the Tygon ${ }^{\mathrm{TM}}$ plastic tube freezes, it expands. A permanent plug at the bottom of the tube is necessary so that the liquid does not escape the tube. Based on personal communication with the local NWS office in Grand Forks, this will be implemented in the next generation.

- Thermal properties and specific density of the water/dye mixture versus plain water need to be defined. Effects of the expansion of the liquid and the plastic tube in the depth reading is unknown. If the expansion is significant, it should be taken into account when the depth markings are labeled on the tube.

- At the end of each summer season, liquid level need to be checked so that zero coincides with the surface. As seen in Figure 2, the liquid level is reduced more than $5 \mathrm{~cm}$ (2 inches). This could be hampered by staffing issue within the local NWS office. This practice could be implemented as part of coop station visit by the Data Administration Program Manager.

- More frequent readings are necessary. There are big gaps between the reading times when the frost depth changes. Daily readings are necessary in spring and fall to capture the gradual increase and decrease in frost depth.

- The freezing point of the liquid used in the tube needs to be verified and accurately defined in laboratory settings outside of the NWS local office ability. It also needs to match the native soil's thermal properties (Ochsner \& Baker, 2008).

- $\quad$ The $1.6 \mathrm{~cm}$ (5/8 inch) PVC housing is separated from the soil with more than $2.5 \mathrm{~cm}$ thick crystalline silica for stability purposes. However, its impact on the native soil's thermal property is unknown. The authors recommend o drying the same soil that came out of the hole and breaking in smaller pieces to back fill the hole (this would require additional trips to the site, or

o using an auger smaller than 5 cm (2 inches) in diameter to minimize the amount of space that needs to be filled, or

o using bentonite clay instead to maintain stability without drastically changing the native soil's thermal properties. This would work well in RRVoN where soil is mostly clay (NRCS, 2008). It may not work well in soil with high sand content. Bentonite clay is commercially available and could be purchased for the Fargo site to do parallel studies.

- The air gap between the $1.0 \mathrm{~cm}(3 / 8$ inch) Tygon ${ }^{\mathrm{TM}}$ plastic tube containing the liquid and the $1.6 \mathrm{~cm}$ (5/8 inch) PVC plastic tube needs to be minimized to eliminate convection in free air. Cold air can easily sit at the bottom of the gap causing NWS probes to overestimate the bottom frost depth. Both in 2007 and 2008, the NWS consistently showed deeper bottom frost depths than the NDAWN estimation suggested. After the achievement of a smaller gap, NWS will have to employ tubing with zero expansion to reduce the risk of jamming.

- Finally, the authors of this paper realize the potential benefits of this application especially in flood forecasting, therefore strongly encourage the NWS to test and calibrate the probes in a laboratory to address these issues before the national implementation. Local NWS offices deploying these practices may need to contact their regional headquarters for regional and federal assistance.

\section{Acknowledgments}

The authors would like to thank Dr. Laura Overstreet, soil scientist in Soil Science Department, North Dakota State University for sharing her expertise on the RRVoN soil properties. 


\section{References}

Casey, F., P. Oduor, H. Hakk, B. Larsen, and T. Desutter, 2008. Transport of 17beta-estradiol and testosterone in a field lysimeter . Soil Science. 173 (7). 456-467.

NRCS. (n.d.). SSSC Soil Survey Labratory Soil Characterization Database. Retrieved July 2008, from http://ssldata.nrcs.usda.gov/

Ochsner, E. T., \& Baker, J. M., 2008. In-Situ Monitoring of Soil Thermal Properties and Heat Flux during Freezing and Thawing. Soil Science Society of America, 72:1025-1032. doi: 10.2136/sssaj2007.0283.

Smerdon, J. E., H. N. Pollack, V. Cermak, J. W. Enz, M. Kresl, J. Safanda, and J. F. Wehmiller, 2006. Dalily, Seasonal and Annual Relationship between air and subsurface temperatures. J. Geophys. Res., 111, D07101, doi: 10.1029/2004JD005578, 2006.

Smerdon, J. E., H. N. Pollack, V. Cermak, J. W. Enz, M. Kresl, J. Safanda, and J. F. Wehmiller, 2004. Air-ground Temperature
Coupling and subsurface Propagation of Annual Temperature Signals. J. Geophys. Res., 109, D21107, doi: 10.1029/2004JD005056.

Smerdon, J. E., H. N. Pollack, J. W. Enz, and M. J. Lewis, 2003. Conduction-dominated Heat Transport of the Annual Temperature Signal in Soil. J. Geophys. Res., 108(B9), 2431, doi: 10.1029/2002JB002351.

Smerdon, J. E., M. J. Lewis, H. N. Pollack, and J. W. Enz, 2002. Spectral Analysis of Air and Ground temperatures at Fargo, North Dakota: Conduction Dominated Propagation of the Annual Frequency Signal. EOS Trans. AGU, 83 (47), Fall Meet. Suppl. Abstract PP51A0304 .

Schmidt, William L., W. D. Gosnold, and J. W. Enz, 2001. A decade of Air-Ground Temperature Exchange from Fargo, North Dakota. Global and Planetary Change. 29:311-325.

US Department of Agriculture. (n.d.). http://uvb.nrel.colostate.edu/UVB/. Retrieved July 2008, from http://uvb.nrel.colostate.edu/UVB/ 


\section{Non-Technical Service Summary for Akyüz, F.A. et al., 2008. NWS Frost Depth Observation with Liquid-In Probes Performance: Two-Year Review.}

\section{The Climate Service Question:}

How did the NWS frost depth probes perform during the first two years of their deployment in North Dakota and are they ready for national deployment?

\section{Background Information:}

The North Central River Forecast Center (NCRFC) currently uses the Sacramento Soil Moisture Accounting (SAC-SMA) model as part of the Advanced Hydrologic Prediction System (AHPS) suite. The SAC-SMA parameterizes the depth of frozen ground in order to calculate the runoff/absorption ratio during spring snow-melt flood scenarios. In order to gain a better understanding of how the frost within the Red River Valley of the North (RRVoN) actually behaves during the spring snow-melt period, the National Weather Service (NWS) in Grand Forks was tasked with the development and deployment of a frost probe network.

\section{Summary of the Research Methodology:}

Performance of the liquid-in frost depth probe made in-house by the Grand Forks National Weather Service (NWS) Weather Forecast Office (WFO) is compared against soil temperature observations made by the North Dakota Agricultural Weather Network (NDAWN) at Fargo location for a two-year period from 2006-2007 to 2007-2008 winter seasons. While the liquid-in frost depth probe provided continuous frost depth observation, NDAWN soil temperature observation had to be interpolated between measurement points to determine the depth where the soil temperature was $0^{\circ} \mathrm{C}\left(32^{\circ} \mathrm{F}\right)$.

\section{Discussion:}

We analyzed the top and the bottom frost depths for two-year period from 2007 to 2008. Since the top frost depth is zero in fall, we only analyzed the top during spring seasons. Our analysis is comprised of comparing frost depths measured by the NWS liquid-in frost depth probe with the frost depths estimated by the NDAWN deep soil temperature profile in Fargo, ND. In this study, estimation is attributed to the NDAWN deep-soil temperature profile because the data were not observed in a spatially continuous setting. Actual frost depths were interpolated linearly within the profile using two measurement points on each side of the estimated frost depth.

Both sets of data, from NWS frost depth probe and the NDAWN data, showed similar trends. However, the magnitude of depths was dissimilar. In general, the NWS frost depth probse suggested deeper bottom frost depths than that of suggested by the NDAWN data.

The main body of the paper includes recommendations to NWS to minimize errors associated with measuring the level at which soil temperature is $0^{\circ} \mathrm{C}\left(32^{\circ} \mathrm{F}\right)$. However, the recommendations are applicable to whoever is willing to measure this depth for varying purposes similar to or other than the NWS objectives. Probe specifications (size, material, properties, etc.) and pictures are provided in the paper. The probe can be built in-house easily with commercially available materials. It is relatively inexpensive compared to commercially available multiple soil temperature probes located at multiple depths under soil surface interfaced to a datalogger for temporally continuous scale. However, one of the most important assets that the NWS frost depth probe possesses is that it provides spatially continuous measurement scales. 